\title{
Fabrication of Nimo Nanostructured Catalyst via Ultrasonic-Assisted Combustion Method Used in High Efficiency Thiophene Hydrodesulfurization: Influence of Organic Compound Type
}

\section{Roya Hamidi}

Tarbiat Modares University

Reza Khoshbin

Buein Zahra Technical University https://orcid.org/0000-0003-3432-441X

Ramin Karimzadeh ( $\sim$ Ramin@modares.ac.ir)

\section{Research Article}

Keywords: Hydrodesulfurization, Organic compound, Combustion, Ultrasonic, Thiophene

Posted Date: June 26th, 2020

DOI: https://doi.org/10.21203/rs.3.rs-37824/v1

License: (c) (i) This work is licensed under a Creative Commons Attribution 4.0 International License.

Read Full License 


\section{Abstract}

Alumina supported NiMo nanocatalysts were synthesized through ultrasonic-assisted combustion method with various organic additives, including citric acid, ethylene glycol, glycine and urea using in hydrodesulfurization of thiophene at atmospheric pressure. The samples were characterized by XRD, TGA, FESEM, EDX, BET-BJH and TPR analyses. The results indicated that the type of organic compound has a noticeable effect on phase structure, surface morphology and reducibility potential as a consequence of different amount of heat and gaseous products released during combustion reaction. Our method showed that a relatively homogeneous distribution of the active material over the support can be achieved. Using citric acid as an organic additive, led to synthesis of nanocatalyst in which more than $90 \%$ of particles are less than $70 \mathrm{~nm}$. The sample synthesized by citric acid exhibited the highest activity in hydrodesulfurization reaction due to its significant properties such as high surface area, considerable surface hole and weakened metal-support interaction compared with other organic additives. In addition, activity assessment of the prepared catalyst by ethylene glycol and glycine demonstrated that $100 \%$ abatement of thiophene can be achieved at $105^{\circ} \mathrm{C}$ and $30 \mathrm{~min}$.

\section{Introduction}

In the new environmental legislation, reduction of sulfur from transportation fuels has become a central issue owing to its negative effects on the atmosphere and human health. Also, sulfur-containing impurities can cause severe corrosion to the reactors and storage vessels [1, 2]. In this regard, strict constraints have been imposed on the oil industry to reduce the sulfur content to less than $10 \mathrm{ppm}$ in the refined products $[3,4]$. Hydrodesulfurization (HDS) is considered the most important process to meet the strict regulation of sulfur elimination [5]. Heterogeneous catalysts based on Mo/W (10-30 wt.\%) promoted by Ni/Co (3-8 wt.\%), located on the edge of $\mathrm{MoS}_{2} / \mathrm{WS}_{2}$ slabs are generally used in the HDS reactions [6, 7]. Various substances have been utilized as support in the HDS process, including zeolites [8], carbon and carbon-based material [9, 10], silica [11] and some metal oxides such as titania [12] and zirconia [13]. Among these, gamma alumina is considered as a distinctive support for HDS reaction due to its low price, sufficient porosity, high mechanical strength, improved thermal stability and accessibility of acid sites [1, 14].

From the literature survey, some strategies for enhancing catalytic performance have been reported, which could be achieved by using various transition metal precursors, utilizing other metals rather than conventional metals, employing novel active phases like nitrides and carbides and using chelating and surfactant agents [15-18]. The incorporation of secondary promotors such as fluorine, boron and phosphate is another beneficial way for improving catalyst activity in the hydrotreating process $[19,20]$. Ebrahimynejad et al. [21], investigated the effect of fluorine content on the catalytic performance of $\mathrm{CoMo} / \mathrm{Al}_{2} \mathrm{O}_{3}$ in the thiophene hydrodesulfurization. Their results demonstrated that the fluorinated prepared catalysts were $75 \%$ more efficient than non-fluorinated samples. According to the literature, several methods have been applied for the preparation of HDS catalysts, classified as precipitation [22], sequential or co-impregnation [23, 24], sol-gel [25], chemical vapor deposition (CVD) [26] and 
hydrothermal deposition [27]. Although these techniques can produce advanced HDS catalysts, they demonstrated disadvantages such as complicated experimental devices, lengthy preparation time, multitudes of preparation steps, high energy requirement, costly substances and environmental contamination [28, 29]. To overcome the aforementioned drawbacks González-Cortés et al. [30], presented an alternative technique for producing HDS catalysts called the combustion method. Their results showed that mono and polymolybdate generation have been facilitated by urea-matrix combustion methodology in comparison with the impregnation and chelating approaches.

The combustion technique is a fast, simple and energy saving method which is based on the redox reaction between an organic compound (fuel) and oxidizer agent, including sulfates, nitrates and carbonates [31, 32]. A wide variety of organic compounds such as urea [33], glycine [34, 35], citric acid [36], ethylene glycol [37], starch[38] and a mixture of them [39] have been used through combustion method.

Due to the evolution of large amount of gases like $\mathrm{CO}_{2}, \mathrm{H}_{2} \mathrm{O}, \mathrm{N}_{2}$, $\mathrm{CO}$ during the combustion process, the as-combusted powders have the foamy and porous structure [39-41]. The physicochemical characteristic of the as-combusted products such as surface area, porous structure, agglomeration and particle size distribution is controlled by the volume of exhausted combustion gases and amount of released heat, which is determined by the type of fuel, heating method and fuel to oxidant ratio [42-45]. The combustion reaction is performed within a short time with the highest temperature of $1500^{\circ} \mathrm{C}$. Such temperature assists the formation of crystalline material that possess individual characteristics [34].

Gonza 'lez-Cortes et al. [46], investigated synthesis of alumina supported bimetallic and trimetallic HDS catalysts via a combustion method by employing urea as organic compound. They concluded that due to the efficient interaction between support and metal species in this method, the HDS performance was enhanced. Jiao et al. [47], synthesized a series of $\mathrm{Co}-\mathrm{Mo} / \mathrm{Al}_{2} \mathrm{O}_{3}-\mathrm{TiO}_{2} \mathrm{HDS}$ catalysts via the combustion (using urea as organic additive) and impregnation methods and reported that as-combusted prepared catalyst had a higher surface area compared with those obtained by impregnation method. In our previous work, $\mathrm{NiMo} / \mathrm{Al}_{2} \mathrm{O}_{3}$ nanocatalysts were fabricated by the combustion method to evaluate the role of citric acid /oxidant ratios on the performance of hydrodesulfurization reaction. It was found that the sample fabricated by citric acid to oxidant ratio of 4 exhibited higher activity compared with other samples [5].

It has been well documented that the utilization of ultrasound irradiation is a desirable technique for catalyst synthesis $[48,49]$. Dissolution, nucleation and growth of crystals can be changed by acoustic cavitation which was driven from ultrasonic power. When a solution is exposed to the ultrasonic waves, small bubbles are generated and enlarged in liquid medium up until they ultimately collapsed. In the collapsing bubbles, local hot spots are formed. Therefore, they provide the reaction energy and ultimately increase the chemical reactivity $[50,51]$. Ultrasound-assisted fabrication of $\mathrm{Co}, \mathrm{Ni}, \mathrm{CoMo}$ and $\mathrm{NiMo}$ catalysts deposited on Al-MCM-41 was investigated by Landau et al. Their results showed that the ultrasonic treatment increased the loading of $\mathrm{MoO}_{3}$ on the pore of Al-MCM and this catalyst was 1.7 
times more active than commercial catalyst used in hydrodesulfurization of dibenzothiophene [52]. Jabbarnezhad et al. [53] studied the effect of ultrasonic on the synthesis of $\mathrm{NiMo} / \mathrm{Al}_{2} \mathrm{O}_{3}-\mathrm{ZrO}_{2}$ catalysts and investigated the catalytic performance in the thiophene HDS conversion. They reported that sonochemically prepared HDS catalysts presented a better catalytic efficiency.

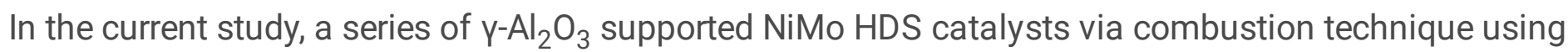
different organic additives including glycine, urea, citric acid and ethylene glycol under ultrasonic irradiation was synthesized. For all we know, there are no former studies that have evaluated the effects of different kinds of organic compounds on the physicochemical properties of ultrasonic-assisted combustion synthesis of HDS catalysts. The characterization of as-combusted powders was assessed using various methods, including XRD, TGA, FESEM, EDX-dot mapping, $\mathrm{N}_{2}$ adsorption-desorption and $\mathrm{H}_{2}$ TPR. Finally, catalytic activity of the prepared NiMo catalyst has been evaluated toward HDS process using thiophene as a model sulfur compound at atmospheric pressure.

\section{Materials And Methods}

Basic chemicals for preparation of catalysts were $y$-Alumina, provided from Ardakan Industrial Ceramic Co. (Yazd, Iran), ammonium heptamolybdate (Merck, 99.3\%) and nickel (II) nitrate hexahydrate (Merck, 99\%) as the sources of Mo and Ni, respectively. Citric acid (Ghatran Shimi, 98\%), ethylene glycol (Neutron, 98\%), glycine (Merck, 99.7\%), urea (Ghatran Shimi, 98\%) and ammonia (Merck, 25\%) were used for the ultrasonic-assisted combustion synthesis. For evaluation of the hydrodesulfurization process, decane (Merck, 99.5\%) and thiophene (Merck, 99\%) were utilized as a solvent and model sulfur compound, respectively. The sulfidation process of synthesized catalysts was done with carbon disulfide and heptane, supplied by Merck Company with purity of $99.9 \%$ and $99 \%$, respectively.

\subsection{Nanocatalyst Preparation and Procedures}

The flowchart of the synthesis steps of $\mathrm{NiMo} / \mathrm{Al}_{2} \mathrm{O}_{3}$ by the combustion method is summarized in Fig. 1.S in the Electronic Supplementary Material. As can be observed in the flowchart, preparation of catalysts has two steps. Initially, a known amount of $\left(\mathrm{NH}_{4}\right)_{6} \mathrm{Mo}_{7} \mathrm{O}_{24} \cdot 4 \mathrm{H}_{2} \mathrm{O}\left(22 \mathrm{wt} . \%\right.$ as $\left.\mathrm{MoO}_{3}\right)$ and $\mathrm{Ni}\left(\mathrm{NO}_{3}\right)_{2}\left(\mathrm{H}_{2} \mathrm{O}\right)_{6}$ (5 wt.\% as $\mathrm{NiO}$ ) were dissolved in a minimum amount of deionized water to prepare an active phase aqueous solution. Then $\mathrm{\gamma}$-alumina powder was added to this solution and stirred for $1 \mathrm{~h}$. In the next step, $\mathrm{NiMo} / \mathrm{Al}_{2} \mathrm{O}_{3}$ was prepared by the ultrasonic-assisted combustion method. For this aim, four different organic compounds at organic additive to oxidant molar ratio of 4 were utilized. For this purpose, 3.39, $1.80,2.42$ and $2.91 \mathrm{~g}$ of organic additives was individually added to the solution in the case of citric acid, ethylene glycol, glycine and urea, respectively. It is worth mention that both $\mathrm{Ni}$ and Mo salts are considered as oxidant. The obtained slurry was stirred at ambient temperature for $1 \mathrm{~h}$. In the following, an aqueous solution of ammonia was added to neutralize $\mathrm{pH}$ of obtained slurry. The sonication was performed with a Topsonics sonicator (Topsonics Co., Iran) using a titanium probe with a constant frequency of $20 \mathrm{kHz}$. The mixture was subjected to ultrasound irradiation at room temperature for $30 \mathrm{~min}$ 
and power $250 \mathrm{~W}$. Then, the resulted slurry was stirred at $80^{\circ} \mathrm{C}$ to obtain a fuel-based paste. Afterward, the obtained pasty mixture was left to a preheated electric furnace for the combustion reaction. Finally, the powders were subjected to calcination in the air stream at $550{ }^{\circ} \mathrm{C}$ for $4 \mathrm{~h}$ to ensure that all the organic additives would decompose. In the current work, the obtained $\mathrm{NiMo} / \mathrm{Al}_{2} \mathrm{O}_{3}$ are referred to NMA $(x)(x=C A$, $E G, G$ and $U$ ) where $x$ indicates the type of organic additives such as citric acid, ethylene glycol, glycine and urea, respectively.

\subsection{Nanocatalyst Characterizations}

The physicochemical properties of fabricated powders were analysed using different characterization methods. X-ray diffraction analysis (XRD) was conducted for phase evaluation on a Philips X'Pert MPD (Netherland) using Cu Ka tube $\left(\lambda=1.5405^{\circ} \mathrm{A}\right)$ working at $40 \mathrm{kV}$ and $40 \mathrm{~mA}$. The spectra were collected in the scanned angle range $(2 \theta)$ of $20^{\circ}-80^{\circ}$ and intervals of $0.02 \%$. The phases formed were recognized by comparing the recorded patterns in standards data base file (JCPDS). The amount of weight loss of synthesized gels was measured by a TGA 209 F3Tarsus apparatus. For this aim, TGA profiles were recorded in the air atmosphere from ambient temperature to $600{ }^{\circ} \mathrm{C}$ with a temperature rise of $10{ }^{\circ} \mathrm{C} \mathrm{min}-$ 1. To collect information about the morphology of NMA (x) series catalysts, FESEM analysis was performed with a Field Emission Scanning Electron Microscope MIRA3 TESCAN instrument operating at $15 \mathrm{kV}$. In order to understand the distribution of metals over the support surface and composition of catalysts, the EDX-dot mapping analysis was undertaken on a MIRA3 TESCAN device fabricated in the Czech Republic.

Textural characteristics of the nanocatalysts were evaluated by nitrogen physisorption at $77 \mathrm{~K}$ using a Micrometric (USA) apparatus. Prior to the experiment, catalysts were outgassed for $2 \mathrm{~h}$ at $200{ }^{\circ} \mathrm{C}$. The surface areas of the samples were derived from Brunauer- Emmett-Teller (BET). The total pore volume was obtained from the amount of nitrogen uptake at relative pressure $\left(P / P_{0}\right) 0.99$. Also, the t-plot method was employed to determine the external surface area. $\mathrm{H}_{2}$-TPR analysis was applied to study the reducibility of the oxidic nanocatalysts with a BELCAT apparatus, which was manufactured in Japan. The experiment was performed in a quartz reactor under a $50 \mathrm{ml} \mathrm{min}^{-1}$ stream of $6.5 \% \mathrm{H}_{2} / \mathrm{Ar}$ up to $900{ }^{\circ} \mathrm{C}$ at a ramp of $10^{\circ} \mathrm{C} \mathrm{min}^{-1}$.

\subsection{Nanocatalyst Performance Test}

The prepared nanocatalysts were sulfided in a continuous fixed-bed reactor operated at $400{ }^{\circ} \mathrm{C}$ for $3 \mathrm{~h}$ at atmospheric pressure with $7 \mathrm{wt}$. \% $\mathrm{CS}_{2}$-heptane mixture. The activity of the sulfided catalysts was evaluated in the hydrodesulfurization of thiophene using a slurry reactor at atmospheric pressure. Figure 2.S in the Electronic Supplementary Material, displays the schematic view of the applied experimental setup. A 35000 ppm thiophene solution in decane was used as model fuel. The $20 \mathrm{mg}$ of sulfided nanocatalyst was poured in a reactor containing model fuel. Then, hydrogen stream with flow

rate of $50 \mathrm{ml} . \mathrm{min}^{-1}$ was injected to the reactor. In specified residence time, the liquid product was collected for sulfur content assessment by a gas chromatography (Teif Gostar Faraz, Iran) equipped with 
a DB-1 column (Agilent) and flame ionization detector (Agilent). Conversion of thiophene as an index of catalytic activity was calculated as follows:

$$
\backslash \text { raisebox1ex } \$ \text { Conversion }=\left(C_{i}-C_{o}\right) \$ \wedge \text { raisebox }-1 \text { ex } \$ C_{i} \$ \times 100
$$

Where $C_{i}$ is the initial thiophene cocenteration $(35000 \mathrm{ppm})$ and $\mathrm{C}_{\mathrm{o}}$ is the final thiophene concentration in the treated product.

\section{Results And Discussions}

\subsection{Characterization of $\mathrm{Ni}-\mathrm{Mo} / \mathrm{Al}_{2} \mathrm{O}_{3}$ Nanocatalyst}

\subsubsection{XRD Analysis}

X-ray diffraction spectra of the as-combusted nanocatalysts in the $2 \theta$ range from $20^{\circ}$ to $80^{\circ}$ are presented in Fig. 1. The peaks at $37.44^{\circ}, 39.67^{\circ}, 42.82^{\circ}, 45.79^{\circ}$ and $67.30^{\circ}$ (JCPDS card 00-004-0880) are due to (311), (222), (321), (400) and (441) crystal planes of $\mathrm{Al}_{2} \mathrm{O}_{3}$, which confirm the cubic structure of alumina. All of the fabricated nanocatalysts display typical characteristics of alumina, denoting that its structure was preserved after the deposition of metals. The diffraction peaks at $2 \theta=23^{\circ}, 25^{\circ}, 25.96^{\circ}$, $33.37^{\circ}, 42.15^{\circ}, 47.02^{\circ}, 48.56^{\circ}$ and $51.3^{\circ}$ are assigned to the monoclinic phase of molybdenum oxide. Also, the position of peaks at $2 \theta$ values of $23.35^{\circ}, 26.58^{\circ}, 27.19^{\circ}, 28.47^{\circ}$ and $32.14^{\circ}$ corresponded to the formation of nickel molybdate in its monoclinic phase.

The nature of the organic additives is responsible for the structural feature of the synthesized catalysts. The quantity of carbon as well as functional groups is distinct in each organic compounds. These factors may change the combustion reaction rate by producing various amounts of heat and gaseous products $[54,55]$.

The high crystallinity of the NMA $(G)$ and NMA $(U)$ samples may be attributed to the high energy released during the combustion reaction of of glycine $\left(-3.24 \mathrm{Kcal} \mathrm{g}^{-1}\right)$ and urea $\left(-2.98 \mathrm{Kcal} \mathrm{g}^{-1}\right)$, respectively, facilitating the growth of crystal facets [55]. On the other side, when citric acid was used, the highest amount of gaseous product was generated which transfers the heat of combustion reaction $(-2.98 \mathrm{Kcal}$ $\mathrm{g}^{-1}$ ) by convection, leading to nucleation of crystallites without any notable growth. It can be said that the amount of released heat and gaseous products through the combustion method compete with each other in influencing the crystallite size of the synthesized catalysts [56]. Ethylene glycol with two hydroxyl group at both ends can make interaction with active metal precursors, hindering their precipitation and accordingly, kept compositional homogeneity along the constituents [57]. Due to the higher boiling point of ethylene glycol compared with water, higher dispersion of $\mathrm{Ni}$ and Mo metals was kept through the drying step. It can be concluded that the small peaks of the mentioned phases in the NMA (CA) and NMA $(E G)$ nanocatalysts might be originated from their high dispersion, which led to the formation of high 
number of active sites. This observation is an important factor for the notable improvement of the HDS process.

(Fig. 1)

\subsubsection{TGA Analysis}

The TGA/ DTG curves of the gel precursors are presented in Fig. 2. According to the TGA/DTG profiles, there are successive weight loss stages in all samples. The weight loss from room temperature until ca. $200{ }^{\circ} \mathrm{C}$ was owing to the elimination of physically adsorbed water on the sample surface and partial dehydration-decomposition of nickel and molybdenum precursors. The second mass reduction is attributed to the total decomposition of $\mathrm{Ni}$ and Mo precursor salts as well as decomposition of remained organic additives resulting in evolution of $\mathrm{CO}_{2}, \mathrm{~N}_{2}$ and $\mathrm{H}_{2} \mathrm{O}$. [6, 33]. The second mass loss which is related to combustion reaction in prepared nanocatalysts with citric acid, urea, glycine and ethylene glycol is $33 \%, 28 \%, 34 \%$ and $12 \%$, respectively. Looking at the Fig. 2(d), it can be said that as urea has a low combustion temperature, it burns rapidly. Also, the decomposition rate of NMA (U) is faster than the equivalent one in the other samples.

According to TGA profiles, no weight loss was observed during $520-600^{\circ} \mathrm{C}$. It can be concluded that all remained volatile compounds were eliminated at temperature above $520^{\circ} \mathrm{C}$. Therefore, to ensure removal of remained organic materials, the as-combusted samples were at calcined $550^{\circ} \mathrm{C}$ for $4 \mathrm{~h}$ in the air atmosphere.

(Fig. 2)

\subsubsection{FESEM Analysis}

In order to investigate the surface morphology, FESEM analysis was used and the representative images of various samples are depicted in Fig. 3 . It can be seen that utilizing the citric acid as organic compound led to construction of considerable surface holes with large pore diameters. The resulted holes originated from escaping large amounts of combustion gases which derived from pyrolysis of high amount of carbon compound in citric acid. It is known that, there is a linear relationship between the carbon number of organic compound (fuel) and the quantity of evolved gas from combustion reaction that influences the porosity of resulted powders [43]. The liberation of gaseous products assists the formation of porous material by limiting the interparticle contact and also, breaks large particles and creates pores between clusters. Additionally, some aggregation with spherical shapes was observed in Fig. 3 (a). According to Fig. 3 (b), the as-combusted nanocatalyst using the ethylene glycol is composed of rod shaped particles which is consistent with the result drown by Nayebzadeh et al. [58], who investigated the influence of fuel type on the formation of carbonated calcium aluminate. Ethylene glycol with two hydroxyl groups on adjacent carbon atoms has a linear structure. Such structure has a positive role in making the appropriate conditions which led to the enhancement of chemical reaction between the used organic additive and oxidant. In other words, ethylene glycol $\left(\mathrm{OH} \mathrm{CH}_{2} \mathrm{CH}_{2} \mathrm{OH}\right)$ can act as a complexing agent which can bond 
to metal ions and form a polymer network [59]. This complex prevents the precipitation of metal hydroxyl groups and maintains the homogeneity of the mixture.

The porous and sponge-like structure is observed in Fig. 3 (c) for the sample fabricated by using glycine as an organic additive. Fathi et al. [40], reported that the simultaneous process of particle formation and the evolution of high quantity of exhaust gases assisted the separation of particles and generated large combustion pores in the sample fabricated by using glycine. In the case of using urea as an organic additive (Fig. 3(d)), the spherical shaped nanoparticles have been aggregated and some cracks are designed across the agglomerates. As seen from TGA analysis, the NMA (U) sample was decomposed rapidly and large amount of heat released via its combustion process which assisted the formation of agglomerated particles. Due to the porous morphologies of the prepared samples, the diffusion of reactants to active sites of the nanocatalysts could be facilitated and accordingly, it can be said that they have an appropriate structure for being used in hydrodesulfurization process. The above observation illustrated that the change in organic compounds has a significant effect on the morphologies of the as combusted synthesized powders as supported by TGA analysis. Figure 4 shows the surface particle size distribution of the prepared sample with citric acid which was investigated by Image-J software. As seen in this figure, the average size is $51.8 \mathrm{~nm}$. In addition, the minimum and maximum particle size of this nanocatalyst have been estimated 16.9 and $107.4 \mathrm{~nm}$, respectively. The major part of particle size of NMA (CA) catalyst is less than $70 \mathrm{~nm}$. Also, the most frequency of distributed surface particle size estimated between 30 and $40 \mathrm{~nm}$ with a frequency of $23.1 \%$. It is worth mention that more than $97 \%$ of the particles have been evaluated less than $100 \mathrm{~nm}$, confirming the formation of the nanometric particle size of the prepared catalysts.

(Fig. 3)

(Fig. 4)

\subsubsection{EDX-analysis}

In order to verify the existence of applied components as well as the distribution of metal species in the catalyst structure, the EDX dot-mapping analysis was carried out. The EDX dot-mapping micrographs of the NMA (CA), NMA (EG), NMA (G) and NMA (U) nanocatalysts have been depicted in Fig. 5. All the elements which have been used in the fabricated samples (nickel, molybdenum, aluminium and oxygen) were detected in the EDX spectra. High distribution of active metals is a notable parameter to make sure the accessibility of reactants to active phase and accordingly high performance of the nanocatalysts. According to Fig. 5, no aggregation of dispersed Mo and Ni elements have been observed for the synthesized samples which means that these species scattered homogeneously over the support. This point demonstrated that all the prepared samples can supply sufficient active phases for the reactant molecules in the HDS process.

(Fig. 5)

\subsubsection{BET Analysis}


Nitrogen adsorption-desorption diagrams along with pore diameter distribution of the support and ascombusted nanocatalysts are displayed in Fig. 6. Based on IUPAC classification, the alumina support and corresponding catalysts presented type IV adsorption/desorption isotherms with $\mathrm{H} 3$ hysteresis loop at high relative pressures, suggesting the slite shaped mesoporous structure [60]. This result indicates that the deposition of $\mathrm{Ni}$ and Mo species on alumina support did not introduce considerable change in the typical shape of the isotherms. It can be concluded that the initial pore structure of the alumina was maintained in the $\mathrm{NiMo} / \mathrm{Al}_{2} \mathrm{O}_{3}$ nanocatalysts.

Considering the Fig. 6, a wide unimodal pore size distribution in the range of 3-40 nm with the most probable pore diameter around $9 \mathrm{~nm}$ was obtained for all catalysts, which made the fabricated catalysts desirable for the reactions containing large molecules. This result is well in agreement with MendozaNieto et al. [6] report, who investigated effect of using citric acid on synthesis of trimetallic HDS catalysts over SBA-15 and alumina .

The textural properties including BET surface area, external surface area, total volume and volume of mesopore which were derived from the $\mathrm{N}_{2}$ adsorption-desorption analysis are summarized in Table 1 . As seen from Table 1, the BET surface area, external surface area and total pore volume of alumina support are $56 \mathrm{~m}^{2} \mathrm{~g}^{-1}, 50 \mathrm{~m}^{2} \mathrm{~g}^{-1}$ and $0.184 \mathrm{~cm}^{3} \mathrm{~g}^{-1}$, respectively. The BET surface areas of NMA (CA), NMA (EG), NMA (G) and NMA (U) were $37,31,36$ and $32 \mathrm{~m}^{2} \mathrm{~g}^{-1}$, respectively. Regarding the alumina support and corresponding catalysts, it can be seen that the NMA (x) series catalysts have smaller textural properties than support. This phenomenon might be derived from the deposition of the metal species into the mesopores of the alumina. According to Table 1, the NMA (CA) and NMA (G) nanocatalysts had higher surface area than the NMA $(E G)$ and NMA (U), owing to increased gaseous products evolution and heat generated from the combustion process, which is in line with results of FESEM analysis. It is well documented that surface area have a key role in catalytic activity which influences the adsorption of reactants on the active phase [7]. Yosefi et al. observed similar results in the fabricating of $\mathrm{MgO} / \mathrm{MgAl}_{2} \mathrm{O}_{4}$ using different organic compounds [43]. Furthermore, by comparing the total pore volume and volume of mesopores of the fabricated nanocatalysts, it could be said that the NMA (CA) sample has superior textural properties than the other fabricated samples. 
Table 1

Textural properties of nanocatalyst synthesized via ultrasonic assisted combustion method using various organic compounds

\begin{tabular}{|lllllll|}
\hline Sample & Fuel type & Fuel ratio & $\mathrm{S}_{\text {BET }}$ & $\left.\mathrm{S}_{\text {Ext(m }} / \mathrm{g}\right)$ & $\left.\mathrm{V}_{\mathrm{t}(\mathrm{cm}} / \mathrm{g}\right)$ & $\left.\mathrm{V}_{\text {meso }(\mathrm{cm}}{ }^{3} / \mathrm{g}\right)$ \\
\hline $\mathrm{Al}_{2} \mathrm{O}_{3}$ & - & - & 56.7 & 50.8 & 0.184 & 0.182 \\
\hline NMA (CA) & Citric acid & 4 & 37.8 & 34.6 & 0.130 & 0.127 \\
\hline NMA (EG) & Ethylene glycol & 4 & 31.9 & 30.5 & 0.111 & 0.110 \\
\hline NMA (G) & Glycine & 4 & 36.2 & 30.0 & 0.118 & 0.116 \\
\hline NMA (U) & Urea & 4 & 32.6 & 30.2 & 0.109 & 0.108 \\
\hline
\end{tabular}

- (Table 1)

- (Fig. 6)

\subsubsection{TPR Analysis}

In order to clarify the interaction between metal species with support and reducibility of the samples, we characterized the synthesized catalysts with temperature program reduction and the recorded $\mathrm{H}_{2}$-TPR profiles are depicted in Fig. 7. The $\mathrm{H}_{2}$-TPR curves of the as-combusted nanocatalysts exhibited different hydrogen consumption peaks. The first reduction peak at $300-600^{\circ} \mathrm{C}$ can be assigned to octahedral molybdenum species weakly bonded to the alumina support. The reduction peaks at $700-1000{ }^{\circ} \mathrm{C}$ can be assigned to subsequent reduction of octahedral Mo species which have strong interaction with support and the reduction of tetrahedrally coordinated Mo oxide. Besides, the reduction peak located at $600-$ $700{ }^{\circ} \mathrm{C}$ has been attributed to the reduction of $\mathrm{Ni}^{2+}$ on the surface of the alumina $[61,62]$.

Compared with the NMA $(U)$ sample, the position of the first two reduction peaks for the NMA (CA) nanocatalyst shifted to a lower temperature, indicating that the reducibility of Mo species has been improved. Considering the $\mathrm{H}_{2}$-TPR profile, it can be said that the NMA (EG) nanocatalyst approximately showed the same $\mathrm{H}_{2}$-TPR position compared with NMA (U). Going from NMA (CA) to NMA (G) nanocatalyst, the shift of the $\mathrm{H}_{2}$-TPR peak toward higher temperatures had occurred. With the exception of NMA $(U)$, the reduction peak at $700-1000^{\circ} \mathrm{C}$ was not observed for the other prepared nanocatalysts. Based on Topsoe model [63], the Ni-Mo-S phase which was formed during the sulfidation process included two structures called type-I and type-II. The monolayer structure of type I bonded strongly with the support, while the multilayer structure of type II had weak interaction with the support and demonstrated superior hydrogenation performance. According to the literatures [2, 64], the lowtemperature reduction peak could be assigned to the precursor of type II active phase which the sulfidation of molybdenum oxide was performed easier. So, it can be concluded that there is the weakened interaction of Mo species over the support in the NMA (CA), NMA (G) and NMA (EG) samples. 
The quantity of metal species which reduced at low temperatures is a significant parameter to improve the catalytic activity in the HDS reaction. Because it is attributed to the amount of the easily reducible metal oxide which could be converted to the catalytically active $\mathrm{MoS}_{2}$ phase through the sulfidation process [6]. To evaluate the quantity of metal species which have been reduced at different temperature intervals, hydrogen consumption in three regions $\left(400-600^{\circ} \mathrm{C}, 600-700^{\circ} \mathrm{C}\right.$ and $\left.700-1000{ }^{\circ} \mathrm{C}\right)$ was also measured (Table 2). The amount of total hydrogen consumption for the deposited $\mathrm{Ni}$ and Mo oxides in the NMA (x) series increased in the following order: NMA (U) $\left(2.99 \mathrm{mmol} \mathrm{g}^{-1}\right) \otimes N M A(G)\left(3.46 \mathrm{mmol} \mathrm{g}^{-1}\right)$ $\triangle N M A(E G)\left(3.52 \mathrm{mmol} \mathrm{g}^{-1}\right) \rrbracket \mathrm{NMA}(\mathrm{CA})\left(3.73 \mathrm{mmol} \mathrm{g}^{-1}\right)$. In addition, the amount of hydrogen consumed at first temperature peak for NMA (EG), NMA (G) and NMA (U) samples were around $5 \%, 7 \%$ and $21 \%$ less than NMA (CA) sample, respectively. This result indicated the formation of well-dispersed metal active phases in the NMA (CA) [61]. It should be noted that, the NMA (U) nanocatalyst showed a peak at a higher temperature, followed by $0.621 \mathrm{mmol} \mathrm{g}^{-1}$ hydrogen consumption, indicating the strong interaction of deposited metal to the alumina support. It can be concluded that the metal species on the NMA (U) catalyst was difficult to reduce compared with those prepared by the other three samples.

Table 2

The reduction behaviour of ultrasonic assisted as-combusted NiMo catalysts with various organic compounds

\begin{tabular}{|c|c|c|c|c|}
\hline \multirow[t]{2}{*}{ Sample } & \multicolumn{4}{|c|}{$\mathrm{H} 2$ consumption $(\mathrm{mmol} / \mathrm{g})^{\mathrm{a}}$} \\
\hline & $400-600^{\circ} \mathrm{C}$ & $600-700^{\circ} \mathrm{C}$ & $700-1000^{\circ} \mathrm{C}$ & Total \\
\hline $\mathrm{NMA}(\mathrm{CA})$ & 1.873 & 1.858 & - & 3.73 \\
\hline NMA (EG) & 1.786 & 1.739 & - & 3.52 \\
\hline NMA (G) & 1.738 & 1.720 & - & 3.46 \\
\hline NMA (U) & 1.476 & 0.893 & 0.621 & 2.99 \\
\hline
\end{tabular}

(Fig. 7)

(Table 2)

\subsection{Comparative Performance of Nanocatalysts toward HDS reaction}

\subsubsection{Effect of Temperature and Time}

The catalytic activity of the ultrasonic assisted as-combusted NMA ( $\mathrm{x}$ ) series nanocatalysts was assessed on a batch reactor at two temperatures $\left(55,105^{\circ} \mathrm{C}\right)$ and reaction times (15 and $\left.30 \mathrm{~min}\right)$. Based on the literature [65], the thiophene HDS proceeds by two main pathways, including direct desulfurization (DSS) and hydrogenation (HYD). In the DDS pathway, the C-S bonds of thiophene molecule are broken 
with hydrogenlysis to form butenes and butadiene. In the HYD pathway, hydrogenation of the aromatic ring takes place before the C-S bond scission and tetrahydrothiophene is formed [66]. Secondary reactions involve hydrogenation of butenes and butadiene and removal of sulfur atoms from tetrahydrothiophene as $\mathrm{H}_{2} \mathrm{~S}$ [66].

The thiophene conversion as a function of temperature at 15 min under atmospheric pressure is presented in Fig. 8. According to this figure, the sulfur removal for the investigated NMA (x) series

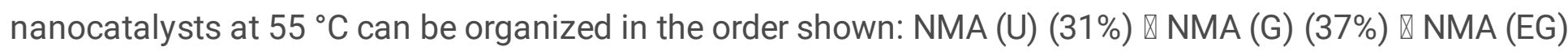
$(39 \%) \otimes N M A(C A)(47 \%)$. By increasing the reaction temperature to $105^{\circ} \mathrm{C}$ the amount of thiophene conversion for NMA (CA), NMA (EG), NMA (G) and NMA (U) nanocatalysts were $89 \%, 83 \%, 81 \%$ and $76 \%$, respectively. It can be seen that the elimination of thiophene molecule notably enhances with the increasing reaction temperature, revealing the thiophene HDS vigorously depends on reaction temperature. This phenomenon is consistent with previous observation [6]. As can be observed, the NMA (CA) nanocatalyst showed maximum sulfur removal which can be explained by its more multi-layered $\mathrm{MoS}_{2}$ slabs and more reducible active sites as evidenced by $\mathrm{H}_{2}$-TPR analysis. Also, the superior activity of NMA (CA) may be related to the high surface area and porous morphology of the NMA (CA), according to $\mathrm{N}_{2}$ adsorption-desorption and FESEM analyses. The porous morphology of the NMA (CA) catalyst plays a positive role in decreasing the mass transfer limitation and made it a promising candidate for the thiophene hydrodesulfurization. Yang et al. [2] observed similar results in their work on the effect of catalyst properties on HDS performance using alumina support.

It can be seen that the activity of NMA (EG) is slightly better than NMA (G). Based on the obtained results from $\mathrm{H}_{2}$-TPR analysis, the higher catalytic activity of NMA (EG) in comparison with NMA (U) can be originated from its better reducibility. It is worth noting that the presence of the reduction peak at $745^{\circ} \mathrm{C}$ for the NMA (U) made it relatively hard to sulfidize this nanocatalyst, which is inadequate for the hydrodesulfurization reaction. Also, the amount of hydrogen consumption in this sample was lower than those of the other three samples.

The hydrodesulfurization activities over the fabricated NMA (x) series at $105^{\circ} \mathrm{C}$ as a function of time are presented in Fig. 9. The results exhibited that, the thiophene conversion of the fabricated nanocatalysts increased with prolonging reaction time which can be attributed to stable catalytic activity through the HDS reaction. The complete conversion was achieved over NMA (CA), NMA (G) and NMA (EG). Results implied that with increase of residence time, the catalytic activity of synthesized samples increased due to the reactant had sufficient time to diffuse into the catalyst structure. However, the thiophene conversion over NMA $(U)$ reached $94 \%$. The better activity of mention catalysts can be addressed to their textural properties. In other words; the pore diffusion resistance of reactants has been eliminated for the catalysts fabricated by citric acid, ethylene glycol and glycine. The conversion of NMA (x) series catalysts in the present study is comparable with the reported results by researchers who had used alumina support in the HDS process. Huang et al. [67] achieved a conversion of $87 \%$ using fixed bed reactor with a solution of $1500 \mathrm{ppm}$ tiophene at $290^{\circ} \mathrm{C}$ and $2.5 \mathrm{MPa}$. In another work, Chao et al. [68] reached a conversion around $80 \%$ at $603 \mathrm{~K}$ and $3.5 \mathrm{Mpa}$ with a model fuel containing thiophene at an initial 
concentration of $1500 \mathrm{ppm}$. In several other studies where the alumina was used as support, even though under harsh operating reaction (temperature, pressure), the catalyst activity was found lower than or equal to those of the current study [69-71]. Beside the excellent performance of the prepared catalysts in this study, they were prepared by a far simpler and faster procedure than all the above mentioned catalysts. This issue makes them a suitable heterogeneous catalyst for hyrodesulfurization process.

(Fig. 8)

(Fig. 9)

\section{Conclusions}

In the current work, bimetallic NiMo nanocatalyst supported on alumina was fabricated through an ultrasonic-assisted combustion method (for the first time). The effects of four various organic additives, namely citric acid, glycine, ethylene glycol and urea on the physicochemical properties of the prepared samples were studied. It is well known that the physicochemical characteristic of the as-combusted products is controlled by the volume of exhausted combustion gases and amount of released heat during combustion process. The obtained results from different analyses demonstrated that surface morphology, mesopore volume, BET surface area and reducibility potential of the catalyst fabricated by citric acid as organic additive (fuel) presented better results than those of the other three organic additives. This issue was indicated by higher sulfur removal of this catalyst in the HDS reaction. According to $\mathrm{H}_{2}$-TPR analysis, the use of citric acid improved the reducibility by decreasing the interaction between deposited metal species and support which suggests the formation of a Ni-Mo-S type II phase. Catalytic performance tests showed that at $105^{\circ} \mathrm{C}$ and $15 \mathrm{~min}$, the amount of sulfur removal was $89 \%$, $83 \%, 81 \%$ and $76 \%$ for samples prepared with citric acid, ethylene glycol, glycine and urea, respectively. Increasing reaction time to 30 min resulted in $100 \%$ conversion of thiophene in the samples synthesized by citric acid, ethylene glycol and glycine, while $94 \%$ conversion has been achieved for the sample synthesized by urea.

Further investigation on the effect of other factors such as ultrasonic irradiation time and power in the preparation step of the ultrasonic-assisted combustion method is recommended for future work.

\section{References}

1. Tanimu A, Alhooshani K (2019) Advanced Hydrodesulfurization Catalysts: A Review of Design and Synthesis. Energy Fuels 33:2810-2838

2. Yang L, Peng C, Fang $X$ et al (2019) Hierarchically macro-mesoporous Ni-Mo/ $\mathrm{Al}_{2} \mathrm{O}_{3}$ catalysts for hydrodesulfurization of dibenzothiophene. Catal Commun 121:68-72

3. Asadi AA, Royaee SJ, Alavi SM et al (2019) Ultra-deep hydrodesulfurization of cracked and atmospheric gasoil blend: Direct and interactive impacts of support composition, chelating agent, metal and promoter loadings. Fuel Process Technol 187:36-51 
4. Klimov OV, Pashigreva AV, Fedotov MA et al (2010) Co-Mo catalysts for ultra-deep HDS of diesel fuels prepared via synthesis of bimetallic surface compounds. J Mol Catal A: Chem 322:80-89

5. Hamidi R, Khoshbin R, Karimzadeh R (2020) Facile fabrication, characterization and catalytic activity of a $\mathrm{NiMo} / \mathrm{Al}_{2} \mathrm{O}_{3}$ nanocatalyst via a solution combustion method used in a low temperature hydrodesulfurization process: the effect of fuel to oxidant ratio. RSC Advances 10:12439-12450

6. Mendoza-Nieto JA, Robles-Méndez F, Klimova TE (2015) Support effect on the catalytic performance of trimetallic NiMoW catalysts prepared with citric acid in HDS of dibenzothiophenes. Catal Today 250:47-59

7. Ebrahiminejad M, Karimzadeh R (2019) Hydrocracking and hydrodesulfurization of diesel over zeolite beta-containing NiMo supported on activated red mud. Adv Powder Technol 30:1450-1461

8. Ding L, Zheng Y, Yang H et al. LCO hydrotreating with Mo-Ni and W-Ni supported on nano- and microsized zeolite beta. ApplCatalA:Gen 2009,353:17-23

9. Whelan J, Katsiotis MS, Stephen S et al (2018) Cobalt-Molybdenum Single-Layered Nanocatalysts Decorated on Carbon Nanotubes and the Influence of Preparation Conditions on Their Hydrodesulfurization Catalytic Activity. Energy Fuels 32:7820-7826

10. Abubakar UC, Alhooshani KR, Adamu S (2019) The effect of calcination temperature on the activity of hydrodesulfurization catalysts supported on mesoporous activated carbon. J Clean Prod 211:1567-1575

11. Phillips DC, Sawhill SJ, Self R et al (2002) Synthesis, characterization, and hydrodesulfurization properties of silica-supported molybdenum phosphide catalysts. J Catal 207:266-273

12. Inoue S, Muto A, Kudou H et al (2004) Preparation of novel titania support by applying the multigelation method for ultra-deep HDS of diesel oil. ApplCatalA:Gen 269:7-12

13. Maity SK, Rana MS, Srinivas BN et al (2000) Characterization and evaluation of $\mathrm{ZrO}_{2}$ supported hydrotreating catalysts. J Mol Catal A: Chem 153:121-127

14. Al-Hammadi SA, Al-Amer AM, Saleh TA. Alumina-carbon nanofiber composite as a support for MoCo catalysts in hydrodesulfurization reactions. Chem Eng J 2018,345:242-251

15. Sahu R, Song BJ, Im JS et al (2015) A review of recent advances in catalytic hydrocracking of heavy residues. J Ind Eng Chem 27:12-24

16. Badoga S, Mouli KC, Soni KK et al (2012) Beneficial influence of EDTA on the structure and catalytic properties of sulfided NiMo/SBA-15 catalysts for hydrotreating of light gas oil. ApplCatalB:Environ 125:67-84

17. Santolalla-Vargas CEa (2015) Effects of $\mathrm{pH}$ and chelating agent on the NiWS phase formation in $\mathrm{NiW} / \mathrm{Y}-\mathrm{Al}_{2} \mathrm{O}_{3} \mathrm{HDS}$ catalysts. Mater Chem Phys 166:105-115

18. Huo Q, Gong Y, Dou T et al (2010) Novel micro- and mesoporous composite molecular sieve assembled by zeolite $L$ nanocrystal and its performance for the hydrodesulfurization (HDS) of fluid catalytic cracking (FCC) gasoline. Energy Fuels 24:3764-3771 
19. Sundaramurthy V, Dalai AK, Adjaye J (2008) The effect of phosphorus on hydrotreating property of $\mathrm{NiMo} / \mathrm{Y}^{-} \mathrm{Al}_{2} \mathrm{O}_{3}$ nitride catalyst. ApplCatalA:Gen 335:204-210

20. Ramírez J, Castillo P, Ceden o L et al (1995) Effect of boron addition on the activity and selectivity of hydrotreating $\mathrm{CoMo} / \mathrm{Al}_{2} \mathrm{O}_{3}$ catalysts. ApplCatalA:Gen 132:317-334

21. Ebrahimynejad M, Haghighi M, Asgari N (2014) Ultrasound Assisted Synthesis and Physicochemical Characterizations of Fluorine-Modified $\mathrm{CoMo} / \mathrm{Al}_{2} \mathrm{O}_{3}$ Nanocatalysts Used for Hydrodesulfurization of Thiophene. J Nanosci Nanotechnol 14:6848-6857

22. Zhang D, Duan A, Zhao $Z$ et al (2010) Preparation, characterization and hydrotreating performances of $\mathrm{ZrO}_{2}-\mathrm{Al}_{2} \mathrm{O}_{3}$-supported NiMo catalysts. Catal Today 149:62-68

23. Kordulis $\mathrm{C}$, Lappas AA, Fountzoula $\mathrm{C}$ et al (2001) NiW/ $\mathrm{Y}-\mathrm{Al}_{2} \mathrm{O}_{3}$ catalysts prepared by modified equilibrium deposition filtration (MEDF) and non-dry impregnation (NDI):Characterization and catalytic activity evaluation for the production of low sulfur gasoline in a HDS pilot plant. ApplCatalA:Gen 209:85-95

24. Zhou W, Wei Q, Zhou Y et al (2018) Hydrodesulfurization of 4,6-dimethyldibenzothiophene over NiMo sulfide catalysts supported on meso-microporous $Y$ zeolite with different mesopore sizes. ApplCatalB:Environ 238:212-224

25. Quartararo J, Amoureux J-P, Grimblot J (2000) Sol-gel synthesis, characterization by solid state NMR and HDS activity of Mo-alumina and Mo-P-alumina based catalysts. J Mol Catal A: Chem 162:353-365

26. Okamoto Y, Kato A, Usman et al (2009) Effect of sulfidation temperature on the intrinsic activity of $\mathrm{Co}_{\mathrm{MoS}}$ and Co-WS 2 hydrodesulfurization catalysts. J Catal 265:216-228

27. Wang $\mathrm{H}$, Fan $\mathrm{Y}$, Shi $\mathrm{G}$ et al (2007) Highly dispersed $\mathrm{NiW} / \mathrm{Y}-\mathrm{Al}_{2} \mathrm{O}_{3}$ catalyst prepared by hydrothermal deposition method. Catal Today 125:149-154

28. Parnianfar $\mathrm{H}$, Masoudpanah SM, Alamolhoda $\mathrm{S}$ et al (2017) Mixture of fuels for solution combustion synthesis of porous $\mathrm{Fe}_{3} \mathrm{O}_{4}$ powders. J Magn Magn Mater 432:24-29

29. Xanthopoulou G, Vekinis G (1998) Investigation of catalytic oxidation of carbon monoxide over a CuCr-oxide catalyst made by self-propagating high-temperature synthesis. ApplCatalB:Environ 19:3744

30. Gonzlez-Corts SL, Xiao TC, Costa PMFJ et al (2004) Urea-organic matrix method: An alternative

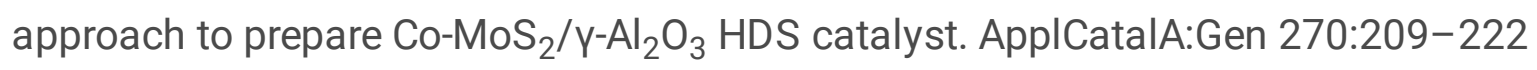

31. Li F-t, Ran J, Jaroniec M et al (2015) Solution combustion synthesis of metal oxide nanomaterials for energy storage and conversion. Nanoscale 7:17590-17610

32. Radpour M, Masoudpanah SM, Alamolhoda S (2017) Microwave-assisted solution combustion synthesis of $\mathrm{Fe}_{3} \mathrm{O}_{4}$ powders. Ceram Int 43:14756-14762

33. Gonzlez-Corts SL, Rodulfo-Baechler SMA, Xiao T et al (2006) Rationalizing the catalytic performance of $\mathrm{y}$-alumina-supported $\mathrm{Co}(\mathrm{Ni})-\mathrm{Mo}(\mathrm{W}) \mathrm{HDS}$ catalysts prepared by urea-matrix combustion synthesis. Catal Lett 111:57-66 
34. Cross A, Roslyakov S, Manukyan KV et al (2014) In Situ Preparation of Highly Stable Ni-Based Supported Catalysts by Solution Combustion Synthesis. J PHYS CHEM C 118:26191-26198

35. Manukyan KV, Cross A, Roslyakov S et al (2013) Solution Combustion Synthesis of Nano-Crystalline Metallic Materials: Mechanistic Studies. J PHYS CHEM C 117:24417-24427

36. Khoshbin $\mathrm{R}$, Haghighi M, Margan $\mathrm{P}$ (2016) Combustion dispersion of CuO-ZnO- $-\mathrm{Al}_{2} \mathrm{O}_{3}$ nanocatalyst over HZSM-5 used in DME production as a green fuel: Effect of citric acid to nitrate ratio on catalyst properties and performance. Energy ConversManage 120:1-12

37. Aranda A, López JM, Murillo R et al (2009) Total oxidation of naphthalene with high selectivity using a ceria catalyst prepared by a combustion method employing ethylene glycol. J Hazard Mater 171:393-399

38. Mohammed MA, Uday MB, Izman S (2020) Effects of calcination temperature and time on the $\mathrm{Ca}_{3} \mathrm{Co}_{4} \mathrm{O}_{9}$ purity when synthesized using starch-assisted sol-gel combustion method. $\mathrm{J}$ Adv Ceram 9:162-172

39. Vahdat Vasei H, Masoudpanah SM, Adeli M et al (2019) Photocatalytic properties of solution combustion synthesized $\mathrm{ZnO}$ powders using mixture of CTAB and glycine and citric acid fuels. Adv Powder Technol 30:284-291

40. Fathi $\mathrm{H}$, Masoudpanah SM, Alamolhoda S et al (2017) Effect of fuel type on the microstructure and magnetic properties of solution combusted $\mathrm{Fe}_{3} \mathrm{O}_{4}$ powders. Ceram Int 43:7448-7453

41. Pehlivan M, Simsek S, Ozbek S et al (2019) An extensive study on the synthesis of iron based magnetic aluminium oxide nanocomposites by solution combustion method. J MATER RES TECHNOL 8:1746-1760

42. Gardey Merino MC, Lascalea GE, Sánchez LM et al (2010) Nanostructured aluminium oxide powders obtained by aspartic acid-nitrate gel-combustion routes. J Alloy Compd 495:578-582

43. Yousefi S, Haghighi M, Rahmani Vahid B (2018) Facile and efficient microwave combustion fabrication of $\mathrm{Mg}$-spinel as support for $\mathrm{MgO}$ nanocatalyst used in biodiesel production from sunflower oil: Fuel type approach. Chem Eng Res Des 138:506-518

44. Nayebzadeh H, Saghatoleslami N, Haghighi M et al (2017) Influence of fuel type on microwaveenhanced fabrication of $\mathrm{KOH} / \mathrm{Ca} 12 \mathrm{Al} 14033$ nanocatalyst for biodiesel production via microwave heating. J Taiwan Inst Chem Eng 75:148-155

45. Nehru LC, Sanjeeviraja C (2014) Rapid synthesis of nanocrystalline $\mathrm{SnO}_{2}$ by a microwave-assisted combustion method. J Adv Ceram 3:171-176

46. Gonzlez-Corts SL, Xiao TC, Lin TW et al (2006) Influence of double promotion on HDS catalysts prepared by urea-matrix combustion synthesis. ApplCatalA:Gen 302:264-273

47. Jiao D, Ma Y, Cao F (2012) Hydrodesulfurization catalyst prepared by urea-matrix combustion method. Particuology 10:468-474

48. Zheng X, Zhu L, Yan A et al (2004) Ultrasound-assisted cracking process to prepare $\mathrm{MoS}_{2}$ nanorods. Ultrason Sonochem 11:83-88 
49. Khoshbin R, Oruji S, Karimzadeh R (2018) Catalytic cracking of light naphtha over hierarchical ZSM-5 using rice husk ash as silica source in presence of ultrasound energy: Effect of carbon nanotube content. Adv Powder Technol 29:2176-2187

50. Khoshbin R, Karimzadeh R (2017) The beneficial use of ultrasound in free template synthesis of nanostructured ZSM-5 zeolite from rice husk ash used in catalytic cracking of light naphtha: Effect of irradiation power. Adv Powder Technol 28:973-982

51. Lee JJ, Kim H, Moon SH (2003) Preparation of highly loaded, dispersed $\mathrm{MoS}_{2} / \mathrm{Al}_{2} \mathrm{O}_{3}$ catalysts for the deep hydrodesulfurization of dibenzothiophenes. ApplCatalB:Environ 41:171-180

52. Landau MV, Vradman L, Herskowitz M et al (2001) Ultrasonically Controlled DepositionPrecipitation: Co-Mo HDS Catalysts Deposited on Wide-Pore MCM Material. J Catal 201:22-36

53. Jabbarnezhad $P$, Haghighi $M$, Taghavinezhad $P$ (2014) Sonochemical synthesis of $\mathrm{NiMo} / \mathrm{Al}_{2} \mathrm{O}_{3}-\mathrm{ZrO}_{2}$ nanocatalyst: Effect of sonication and zirconia loading on catalytic properties and performance in hydrodesulfurization reaction. Fuel Process Technol 126:392-401

54. de Souto Viana KM, Dantas BB, Nogueira NAS et al (2010) Influence of Fuel in the Synthesis of $\mathrm{ZnAl}_{2} \mathrm{O}_{4}$ Catalytic Supports by Combustion Reaction. Mater Sci Forum 660-661:52-57

55. Sutka A, Mezinskis G (2012) Sol-gel auto-combustion synthesis of spinel-type ferrite nanomaterials. Front Mater Sci 6:128-141

56. Palneedi $H$, Mangam V, Das $S$ et al (2011) Effect of fuel-to-nitrate ratio on the powder characteristics of nanosized $\mathrm{CeO}_{2}$ synthesized by mixed fuel combustion method. J Alloy Compd 509:9912-9918

57. Chen W, Li F, Yu J (2006) Combustion synthesis and characterization of nanocrystalline $\mathrm{CeO}_{2}$-based powders via ethylene glycol-nitrate process. Mater Lett 60:57-62

58. Nayebzadeh H, Haghighi M, Saghatoleslami N et al (2018) Fabrication of carbonated alumina doped by calcium oxide via microwave combustion method used as nanocatalyst in biodiesel production: Influence of carbon source type. Energy ConversManage 171:566-575

59. Zhang G, Liu M (1999) Preparation of nanostructured tin oxide using a sol-gel process based on tin tetrachloride and ethylene glycol. J Mater Sci 34:3213-3219

60. Rahmani Vahid B, Haghighi M (2017) Biodiesel production from sunflower oil over $\mathrm{MgO} / \mathrm{MgAl}_{2} \mathrm{O}_{4}$ nanocatalyst: Effect of fuel type on catalyst nanostructure and performance. Energy ConversManage 134:290-300

61. Cui Q, Zhou Y, Wei Q et al (2013) Performance of Zr- and P-modified USY-based catalyst in hydrocracking of vacuum gas oil. Fuel Process Technol 106:439-446

62. Lai W, Song W, Pang $L$ et al (2013) The effect of starch addition on combustion synthesis of NiMo$\mathrm{Al}_{2} \mathrm{O}_{3}$ catalysts for hydrodesulfurization. J Catal 303:80-91

63. Topsøe H, Clausen BS, Candia R et al (1981) In situ Moessbauer emission spectroscopy studies of unsupported and supported sulfided Co-Mo hydrodesulfurization catalysts: Evidence for and nature of a Co-Mo-S phase. J Catal 68:433-452 
64. Yin H, Liu X, Yao Y et al (2015) Nanosized HY zeolite-alumina composite support for hydrodesulfurization of FCC diesel. J Porous Mater 22:29-36

65. Salnikov OG, Burueva DB, Barskiy DA et al. A Mechanistic Study of Thiophene Hydrodesulfurization by the Parahydrogen-Induced Polarization Technique. ChemCatChem 2015,7:3508-3512

66. Wang H, Iglesia E (2010) Thiophene hydrodesulfurization catalysis on supported Ru clusters: Mechanism and site requirements for hydrogenation and desulfurization pathways. J Catal 273:245-256

67. Huang Y, Zhou Z, Qi Y et al. Hierarchically macro-/mesoporous structured $\mathrm{Co}-\mathrm{Mo}-\mathrm{Ni} / \mathrm{Y}-\mathrm{Al}_{2} \mathrm{O}_{3}$ catalyst for the hydrodesulfurization of thiophene. Chem Eng J 2011,172:444-451

68. Liu C, Zhou Z, Huang Y et al (2014) Support Effects on Thiophene Hydrodesulfurization over Co-Mo$\mathrm{Ni} / \mathrm{Al}_{2} \mathrm{O}_{3}$ and $\mathrm{Co}-\mathrm{Mo}-\mathrm{Ni} / \mathrm{TiO}_{2}-\mathrm{Al}_{2} \mathrm{O}_{3}$ Catalysts. CHINESE J CHEM ENG 22:383-391

69. Ashenaeian S, Haghighi M, Rahemi N (2019) Hybrid plasma-sono-coprecipitation dispersion of NiMo nanocatalyst over functionalized multiwall carbon nanotube used in hydrodesulfurization of thiophene. Adv Powder Technol 30:502-512

70. Obeso-Estrella R, Fierro JLG, de León JND et al (2018) Effect of partial Mo substitution by W on HDS activity using sulfide $\mathrm{CoMoW} / \mathrm{Al}_{2} \mathrm{O}_{3}-\mathrm{TiO}_{2}$ catalysts. Fuel 233:644-657

71. Ayala -GM, Puello PE, Quintana $P$ et al (2015) Comparison between alumina supported catalytic precursors and their application in thiophene hydrodesulfurization: $\left(\mathrm{NH}_{4}\right)_{4}\left[\mathrm{NiMo}_{6} \mathrm{O}_{24} \mathrm{H}_{6}\right] \cdot 5 \mathrm{H}_{2} \mathrm{O} / \mathrm{Y}^{-}$ $\mathrm{Al}_{2} \mathrm{O}_{3}$ and $\mathrm{NiMoOx} / \mathrm{Y}-\mathrm{Al}_{2} \mathrm{O}_{3}$ conventional systems. RSC Adv 5:102652-102662

\section{Tables}

Table 1: Textural properties of nanocatalyst synthesized via ultrasonic assisted combustion method using various organic compounds

\begin{tabular}{|lllllll|}
\hline Sample & & & $\mathrm{S}_{\mathrm{BET}}$ & $\mathrm{S}_{\text {Ext }\left(\mathrm{m}^{2} / \mathrm{g}\right)}$ & $\left.\mathrm{V}_{\mathrm{t}(\mathrm{cm}}{ }^{3} / \mathrm{g}\right)$ & $\left.\mathrm{V}_{\text {meso }(\mathrm{cm}}{ }^{3} / \mathrm{g}\right)$ \\
& Fuel type & Fuel ratio & $\left(\mathrm{m}^{2} / \mathrm{g}\right)$ & & & \\
\hline $\mathrm{Al}_{2} \mathrm{O}_{3}$ & - & & & & & \\
\hline $\mathrm{NMA}(\mathrm{CA})$ & Citric acid & 4 & 36.7 & 50.8 & 0.184 & 0.182 \\
\hline $\mathrm{NMA}(\mathrm{EG})$ & Ethylene glycol & 4 & 31.9 & 30.5 & 0.111 & 0.110 \\
\hline $\mathrm{NMA}(\mathrm{G})$ & Glycine & 4 & 36.2 & 30.0 & 0.118 & 0.116 \\
\hline NMA (U) & Urea & 4 & 32.6 & 30.2 & 0.109 & 0.108 \\
\hline
\end{tabular}


Table 2: The reduction behaviour of ultrasonic assisted as-combusted NiMo catalysts with various organic compounds

\begin{tabular}{|c|c|c|c|c|}
\hline \multirow[t]{2}{*}{ Sample } & \multicolumn{4}{|c|}{$\mathrm{H} 2$ consumption $(\mathrm{mmol} / \mathrm{g})^{\mathrm{a}}$} \\
\hline & $400-600^{\circ} \mathrm{C}$ & $600-700{ }^{\circ} \mathrm{C}$ & $700-1000{ }^{\circ} \mathrm{C}$ & Total \\
\hline $\operatorname{NMA}(\mathrm{CA})$ & 1.873 & 1.858 & - & 3.73 \\
\hline NMA (EG) & 1.786 & 1.739 & - & 3.52 \\
\hline NMA (G) & 1.738 & 1.720 & - & 3.46 \\
\hline NMA (U) & 1.476 & 0.893 & 0.621 & 2.99 \\
\hline
\end{tabular}

Figures 


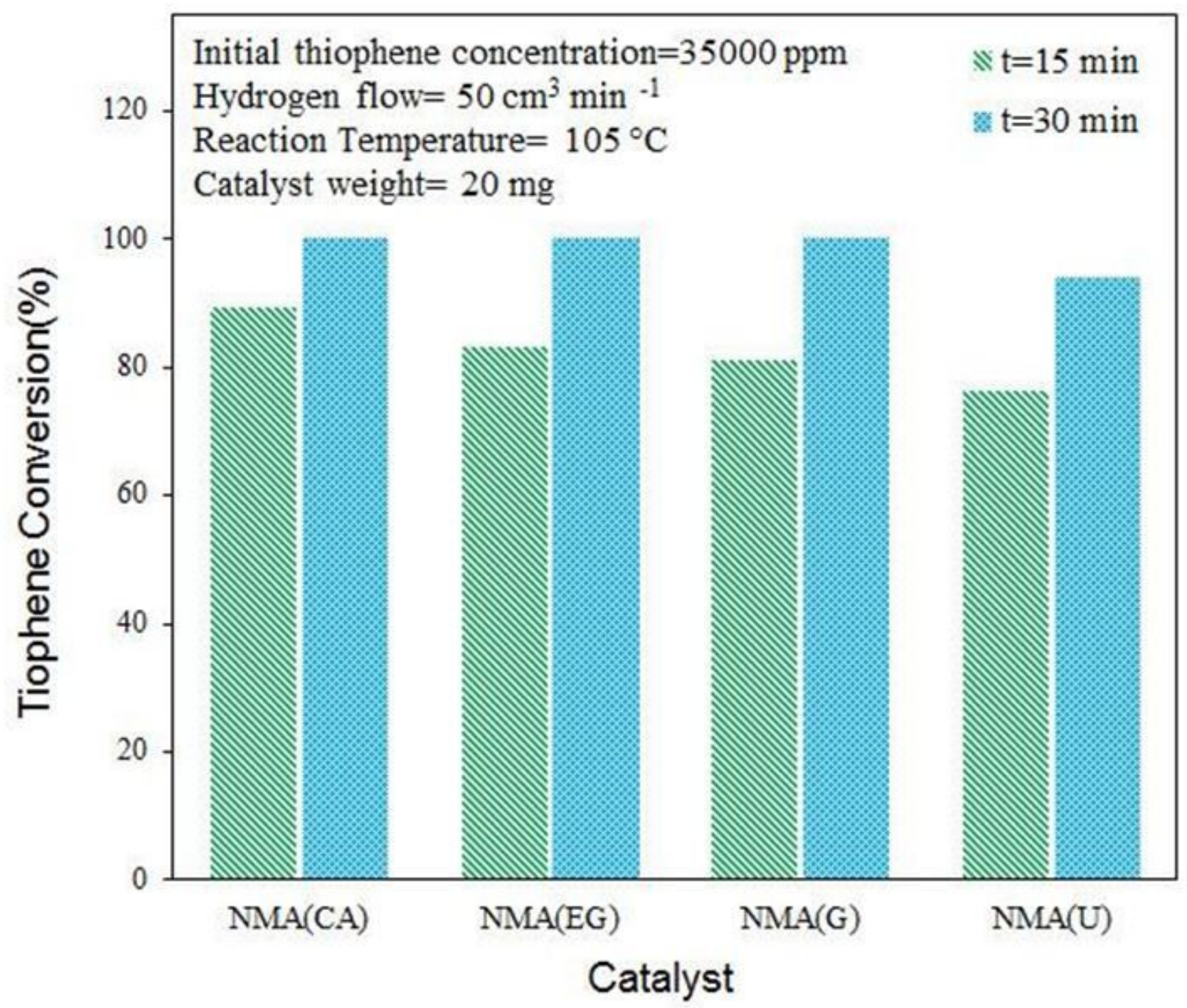

Figure 1

Influence of fuel type toward hydrodesulfurization of thiophene over ultrasonic assisted combustion fabricated NiMo/Al2O3 nanocatalysts at $105^{\circ} \mathrm{C}$ 


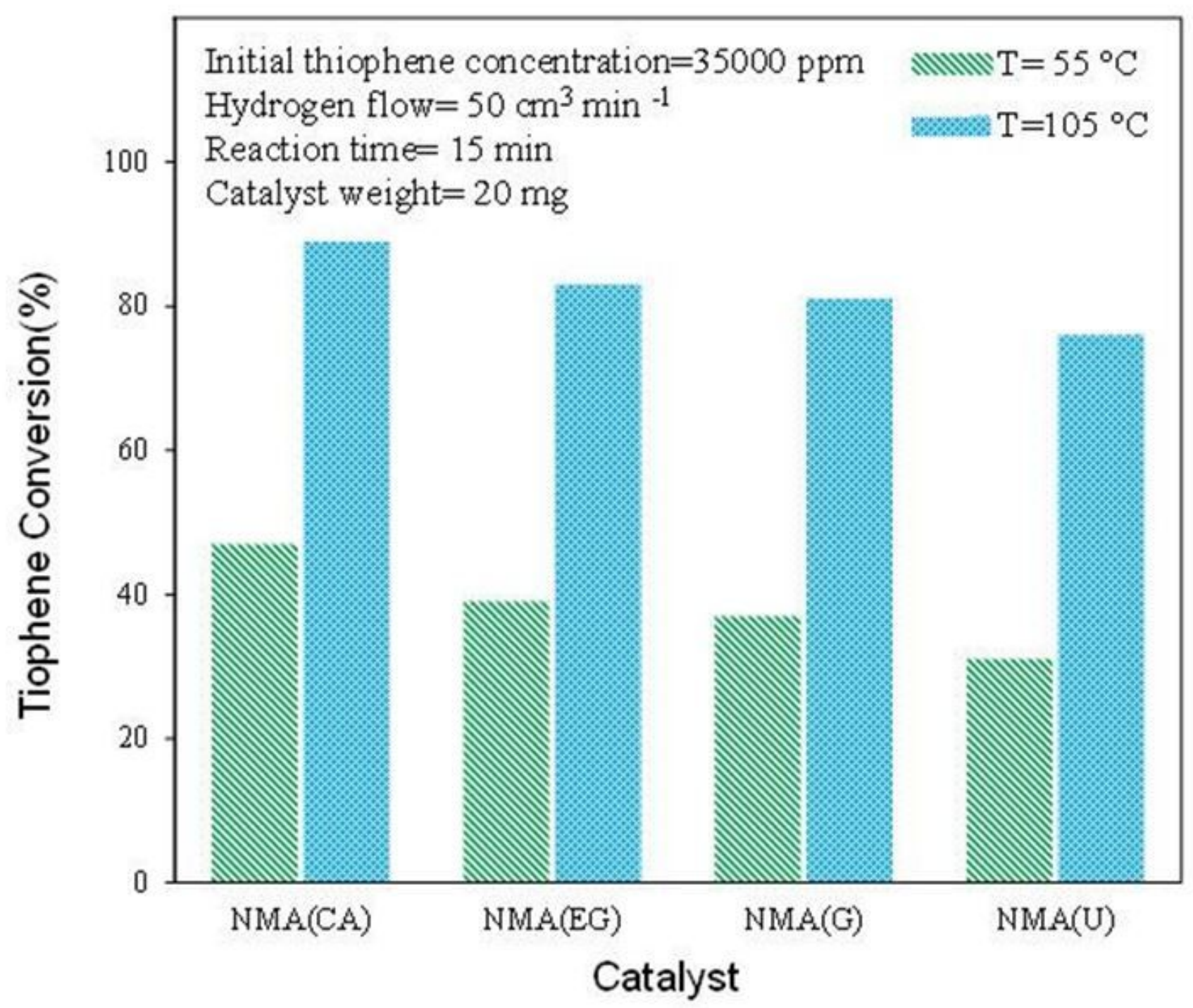

Figure 2

Influence of fuel type toward hydrodesulfurization of thiophene over ultrasonic assisted combustion fabricated NiMo/Al2O3 nanocatalysts at $15 \mathrm{~min}$ 


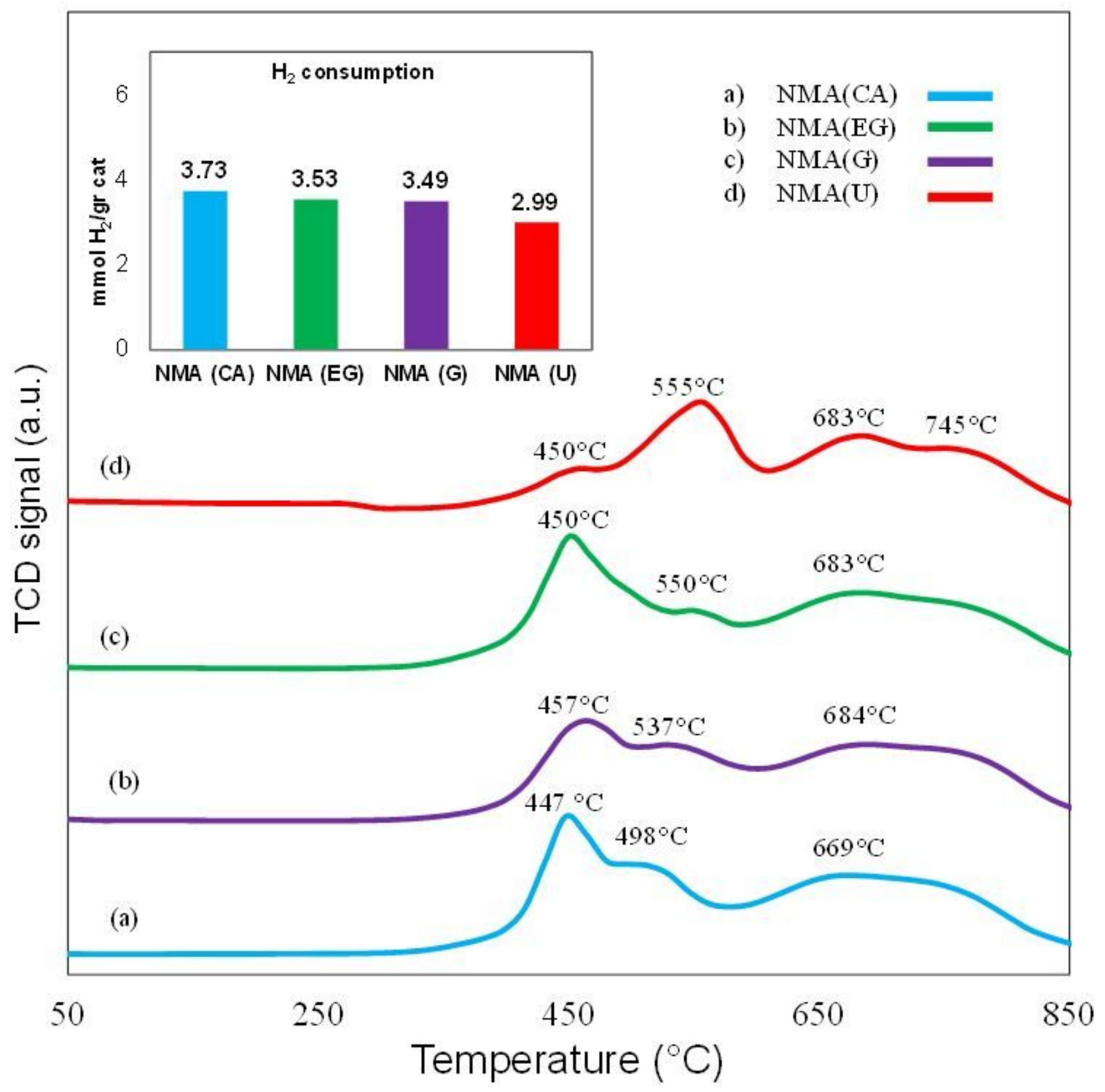

Figure 3

TPR analysis of nanocatalysts fabricated via ultrasonic assisted combustion method a)NMA(CA), b)NMA $(E G), c) N M A(G), d) N M A(U)$. 

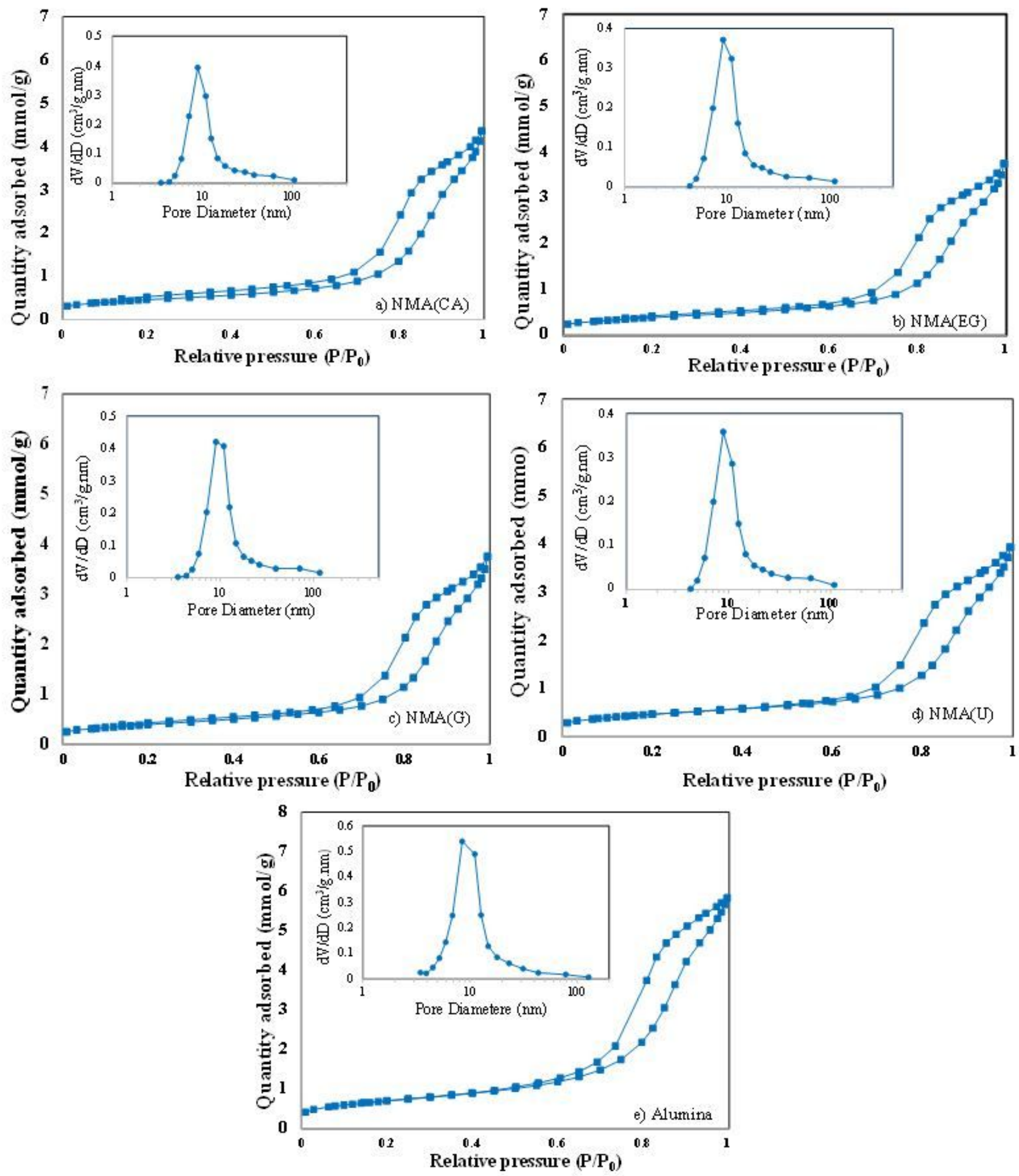

Figure 4

N2 adsorption-desorption isotherm of fabricated catalysts with different organic compounds 

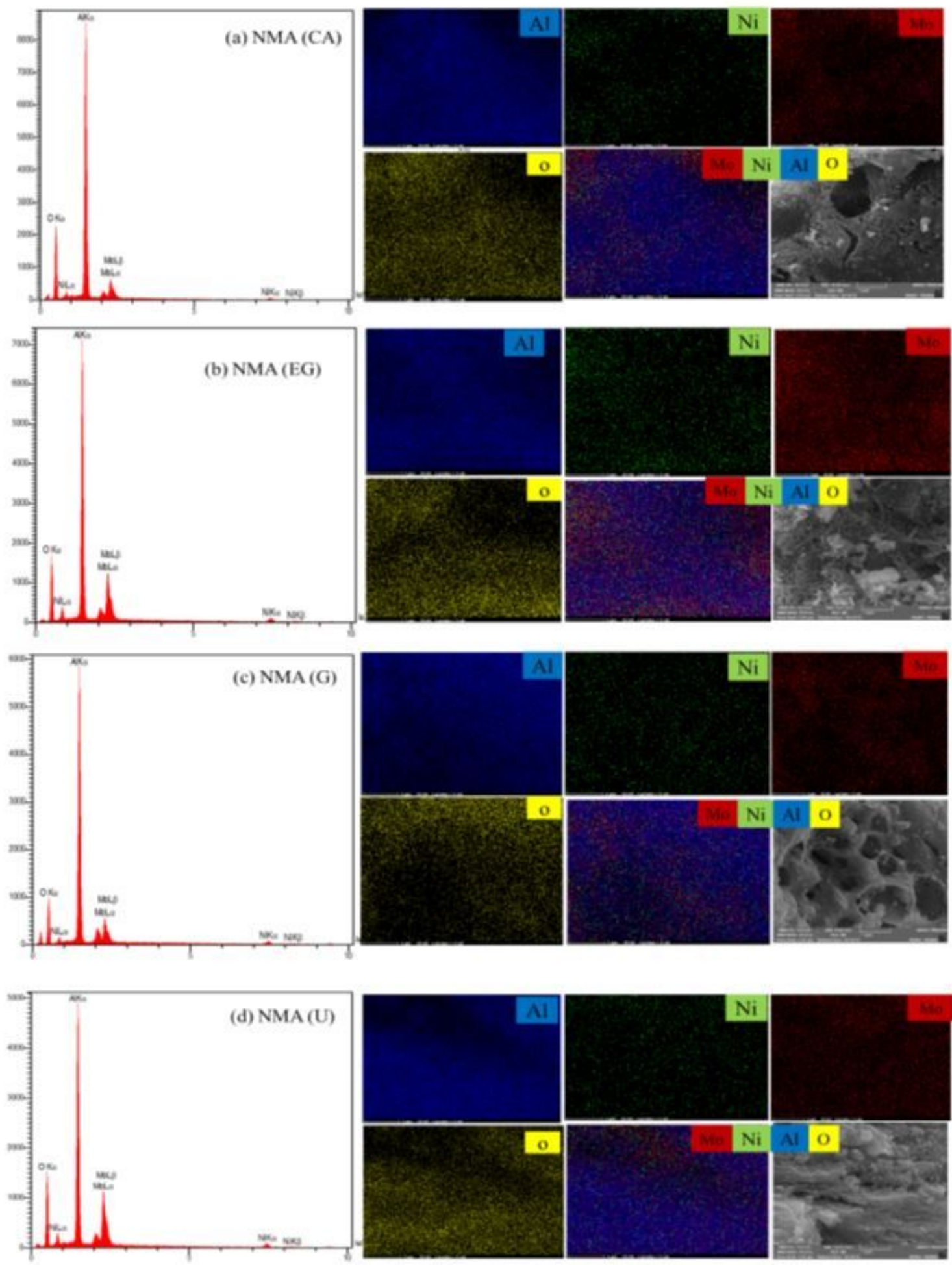

Figure 5

EDX analysis of nanocatalysts fabricated via ultrasonic assisted combustion method a)NMA(CA), b)NMA $(E G), c) N M A(G), d) N M A(U)$. 

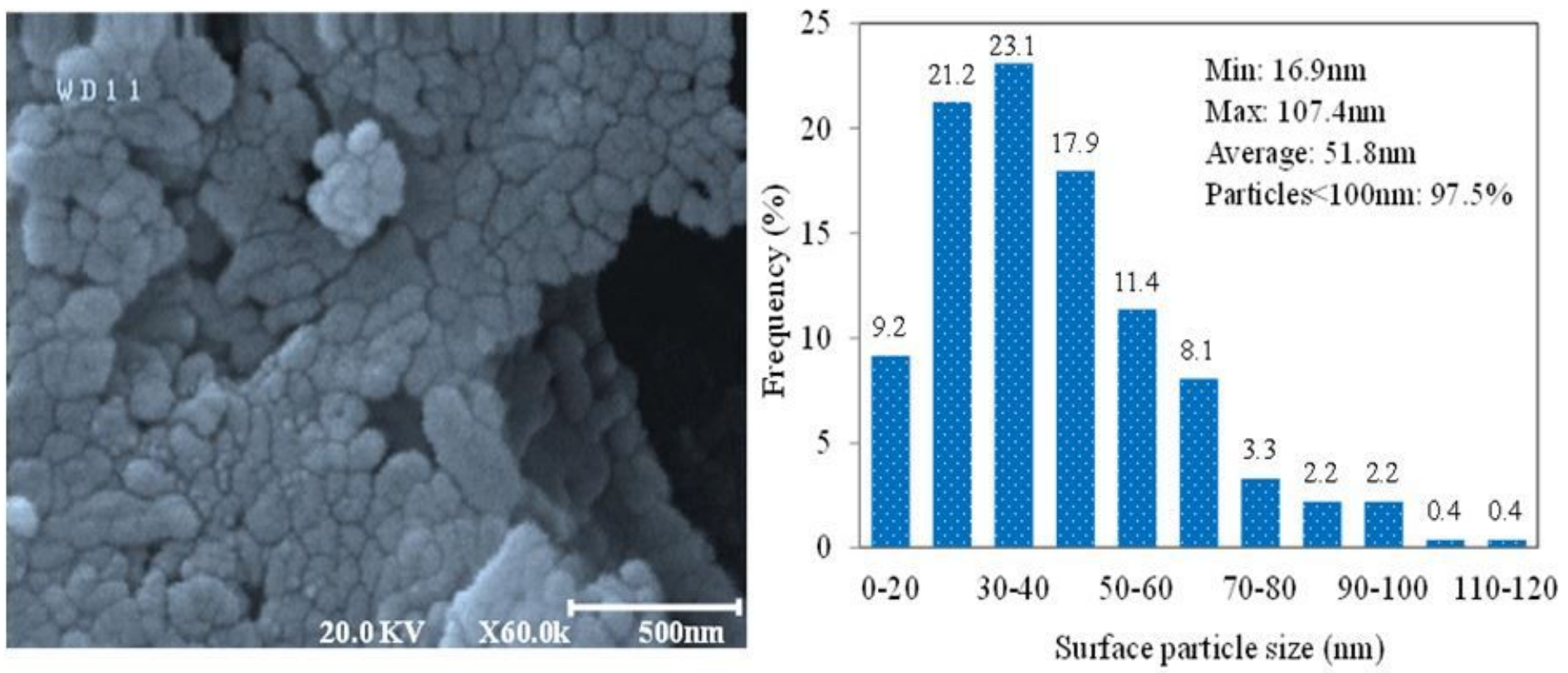

Figure 6

Surface particle size histogram of NMA )CA( 


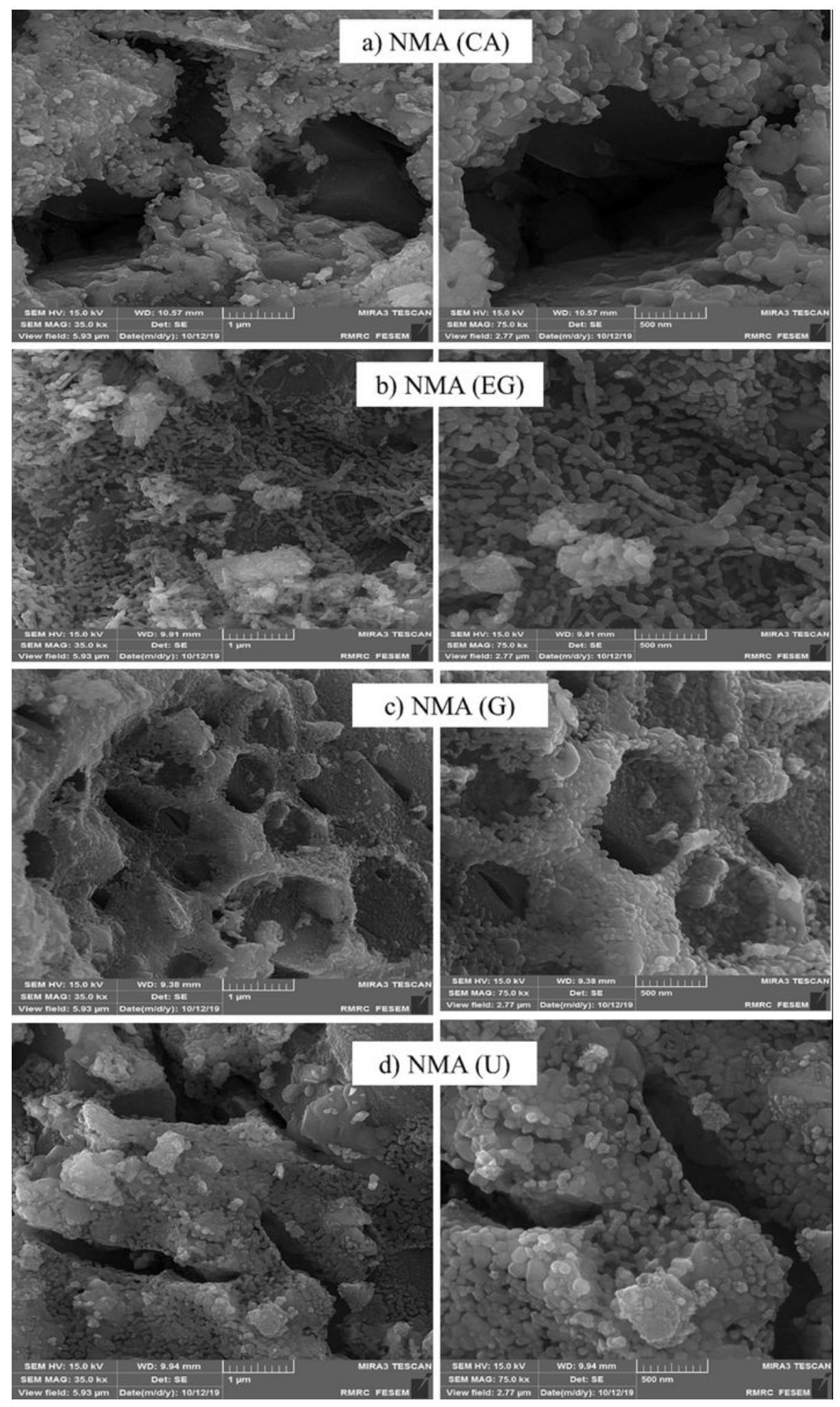

\section{Figure 7}

FESEM images of nanocatalysts fabricated via ultrasonic assisted combustion method a)NMA(CA), b)NMA (EG), c)NMA (G), d)NMA (U). 


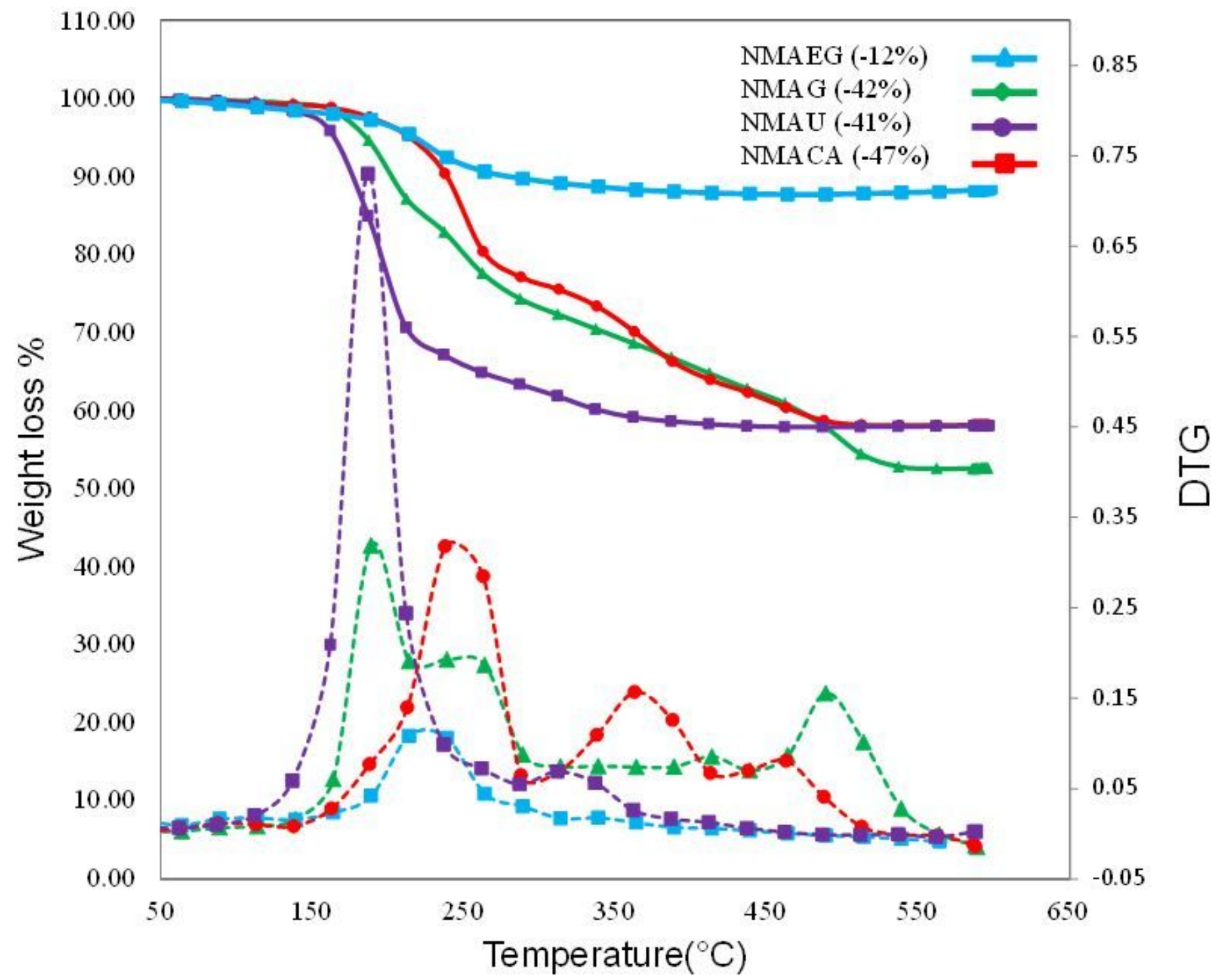

Figure 8

TGA/DTG plots of alumina supported NiMo oxidic precursors using different organic compounds 


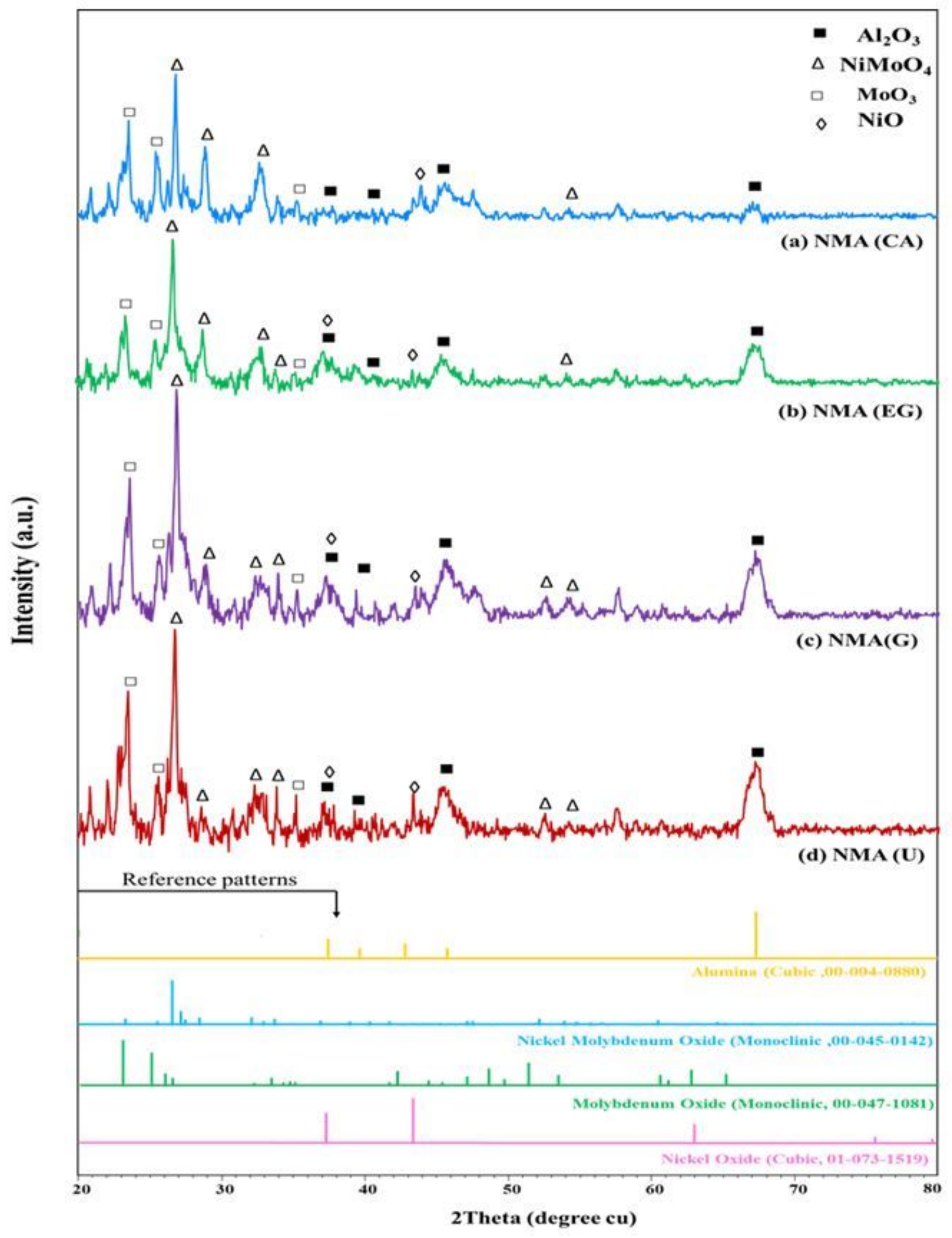

Figure 9

XRD patterns of nanocatalysts fabricated via ultrasonic assisted combustion method a)NMA(CA), b)NMA $(E G), c) N M A(G), d) N M A(U)$.

\section{Supplementary Files}


This is a list of supplementary files associated with this preprint. Click to download.

- Supllementaryfile.docx 